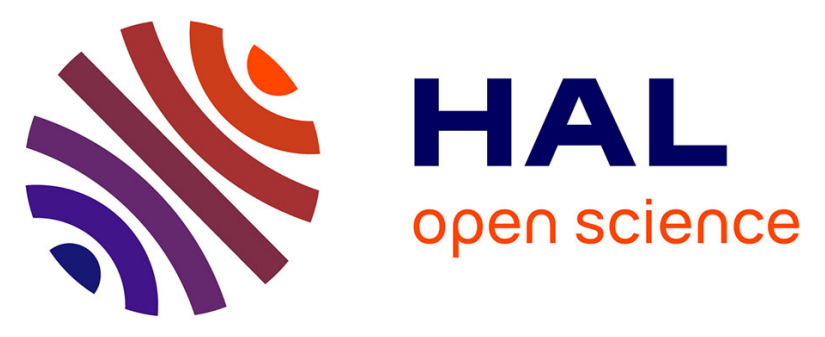

\title{
Modelling of the gas-liquid partitioning of aroma compounds during wine alcoholic fermentation and prediction of aroma losses
}

Sumallika Morakul, Jean-Roch Mouret, Nicole Pamela, Cristian Trelea, Jean-Marie Sablayrolles, Violaine Athes

\section{To cite this version:}

Sumallika Morakul, Jean-Roch Mouret, Nicole Pamela, Cristian Trelea, Jean-Marie Sablayrolles, et al.. Modelling of the gas-liquid partitioning of aroma compounds during wine alcoholic fermentation and prediction of aroma losses. Process Biochemistry, 2011, 46 (5), pp.1125-1131. 10.1016/j.procbio.2011.01.034 . hal-01003250

\section{HAL Id: hal-01003250 \\ https://hal.science/hal-01003250}

Submitted on 12 Jul 2017

HAL is a multi-disciplinary open access archive for the deposit and dissemination of scientific research documents, whether they are published or not. The documents may come from teaching and research institutions in France or abroad, or from public or private research centers.
L'archive ouverte pluridisciplinaire HAL, est destinée au dépôt et à la diffusion de documents scientifiques de niveau recherche, publiés ou non, émanant des établissements d'enseignement et de recherche français ou étrangers, des laboratoires publics ou privés. 
1 Modelling of the gas-liquid partitioning of aroma compounds during wine alcoholic

2 fermentation and prediction of aroma losses

3

4 Sumallika Morakul $^{\mathrm{a}}$, Jean-Roch Mouret ${ }^{\mathrm{a}}$, Pamela Nicolle ${ }^{\mathrm{b}}$, Ioan Cristian Trelea ${ }^{\mathrm{c}}$, Jean-

$5 \quad$ Marie Sablayrolles ${ }^{\mathrm{a}}$, Violaine Athes ${ }^{\mathrm{c} *}$

6

$7 \quad{ }^{a}$ INRA, UMR 1083, 2 Place Viala, F-34060 Montpellier Cedex 1, France

$8 \quad$ b INRA, UE 999, F-11430 Gruissan, France

$9 \quad{ }^{\mathrm{c}}$ AgroParisTech, INRA, UMR 782, F-78850 Thiverval-Grignon, France

10

$11 *$ Corresponding author

$12 \quad$ Tel. : + 33130815383

$13 \quad$ Fax. : +33130815597

14 e-mail : vathes@grignon.inra.fr 


\section{ABSTRACT}

A model was elaborated to quantify the gas-liquid partitioning of four of the most important

volatile compounds produced during winemaking fermentations, namely isobutanol, ethyl acetate, isoamyl acetate and ethyl hexanoate. Analyses of constant rate fermentations demonstrated that the partitioning was not influenced by the $\mathrm{CO}_{2}$ production rate and was a function of only the must composition and the temperature. The parameters of the model were identified in fermentations run at different temperatures, including anisothermal conditions. The prediction of the partition coefficient $\left(\mathrm{k}_{\mathrm{i}}\right)$ by the model was very accurate for isobutanol, isoamyl acetate and ethyl hexanoate. The technological potential of the model was confirmed by using it to calculate the losses of volatiles in the gas phase during fermentation and comparing them with experimental data. Up to $70 \%$ of the produced volatile compounds were lost. The difference between observed losses and losses estimated from predicted $\mathrm{k}_{\mathrm{i}}$ values never exceeded 3\%.

Keywords: gas-liquid transfer, online GC measurement, wine, aroma, dynamic modelling 


\section{Introduction}

The synthesis of higher alcohols and esters during fermentation makes an important contribution to wine quality and the control of the production of these volatile compounds is one of the major ways to control the organoleptic characteristics of wine. The higher alcohols are undesirable at high concentrations, but in smaller quantities they are thought to contribute positively to overall wine quality. Esters have a significant effect on the fruity flavour in wine. The esters making the largest olfactory impact are ethyl acetate, isoamyl acetate, isobutyl acetate, ethyl hexanoate and 2- phenylethyl acetate [1]. Varietal aromas —volatile compounds derived from non-volatile precursors in the grape which are released by the yeast during fermentation, such as thiols - also play an essential role in wine aroma but they are usually present at very low concentrations and are therefore more difficult to quantify.

The concentrations of volatiles at the end of fermentation depend primarily on their synthesis by the yeasts but may also be significantly modified by losses into the exhausted $\mathrm{CO}_{2}$. Therefore, understanding and modelling the transfer of aroma compounds between the gas and liquid phases would be extremely useful, and the calculation of balances differentiating the microbiological process of production and the physicochemical process of transfer into the exhausted $\mathrm{CO}_{2}$ is central to this issue. The online monitoring of volatile compounds in the tank headspace, as recently proposed by Mouret et al. [2], allows online estimation of volatile concentrations in fermenting musts, provided that reliable models for gas-liquid partitioning are available for all phases of the fermentation process. Finally, such models could subsequently be coupled to predictive models of volatile compound synthesis, based on knowledge of the biochemical pathways involved. Indeed, some authors have already proposed such models in beer making conditions [3-5]. 
Several models have been developed to quantify the transfer of volatile molecules between aqueous solutions and gas phases [6-8]. However, none of them is directly applicable to winemaking conditions. Indeed, unlike the conditions considered in these established models, the concentrations of volatile molecules, as well as the overall composition of the fermenting must, are continuously changing during alcoholic fermentations. Another difference is the production and release of $\mathrm{CO}_{2}$, bubbles of which increase the transfer from the liquid to the gas, by stripping. Finally, only 3 molecules (isobutyl acetate, acetaldehyde and ethyl acetate) out of 21 were of interest in wine fermentations.

Several authors have studied flavour release in the context of oenology but mostly focused on the partitioning properties of volatiles in final wines [9-11] and did not consider their behaviour during fermentation. Recently, Morakul et al. [12] evaluated the effect of the matrix changes (mainly corresponding to the consumption of sugar and the production of ethanol) and of the temperature on gas-liquid partitioning in model conditions simulating fermenting musts. Ferreira et al. [13] assessed volatile compound losses due to the $\mathrm{CO}_{2}$ production and showed that up to $80 \%$ of some molecules could be blown off; however, the experimental conditions used in [13] were not completely representative of the fermentation conditions, because changes in the matrix composition were not considered and the stripping rate was much higher than usually observed in winemaking.

In this paper, the objective was to develop a model of the evolution of the partition coefficient between the gas and liquid phases of four major volatile molecules, (ethyl acetate, isoamyl acetate, ethyl hexanoate and isobutanol) in winemaking fermentations. The partition coefficient $\mathrm{k}_{\mathrm{i}}$ is expressed as the ratio between the mass concentration of the compound in the gas phase $\left[C_{i}^{g a s}\right.$ in $\left.\mathrm{mg} / \mathrm{L}\right]$ and that in the liquid phase $\left[C_{i}^{\text {liq }}\right.$ in $\left.\mathrm{mg} / \mathrm{L}\right]$ at equilibrium.

The work was focused on these four molecules because they are representative of higher alcohol and ester families. Isobutanol is one of the major fusel alcohols whose concentrations 
in wines are several tens of $\mathrm{mg} / \mathrm{L}$. It is synthesized by the yeasts from amino acids, in particular valine, and from keto-acids. As most higher alcohols are weakly volatile, its partition coefficient $\left(\mathrm{k}_{\mathrm{i}}\right)$, expressed as a mass concentration ratio, at $25^{\circ} \mathrm{C}$ in grape musts is around $6.8 \times 10^{-4}[12]$. Despite its high concentration in the liquid phase, it is often below its perception threshold in gas [1]. Ethyl acetate, isoamyl acetate, and ethyl hexanoate are well known for their contribution to the fruity aroma of wines [14]. Their concentrations in wines are usually low $(20-60 \mathrm{mg} / \mathrm{L}$ for ethyl acetate and less than $10 \mathrm{mg} / \mathrm{L}$ for isoamyl acetate and ethyl hexanoate) but nevertheless always above their perception thresholds [1]. The $\mathrm{k}_{\mathrm{i}}$ values at $25^{\circ} \mathrm{C}$ in grape musts are around $1.0 \times 10^{-2}$ for ethyl acetate, $2.9 \times 10^{-2}$ for isoamyl acetate and $4.5 \times 10^{-2}$ for ethyl hexanoate[12].

After assessing the effects of the main factors involved, and in particular the impact of stripping by $\mathrm{CO}_{2}$, the model for the prediction of the partition coefficient $\left(\mathrm{k}_{\mathrm{i}}\right)$ was developed and then validated in different winemaking situations. The model was then used to estimate the losses of volatile compounds in several winemaking situations.

\section{Material and methods}

\subsection{Fermentations}

\subsubsection{Yeast strains}

The Saccharomyces cerevisiae strains EC1118 and K1 were used. These commercial wine yeasts are produced as active dry yeast by Lallemand SA. Each fermentation tank was inoculated with $0.2 \mathrm{~g} / \mathrm{L}$ of active dry yeast previously rehydrated for 30 minutes at $35^{\circ} \mathrm{C}$.

\subsubsection{Musts}


Various grape musts from the South of France were used. They were flash-pasteurised and stored under sterile conditions. Their sugar concentrations were between 180-200 g/L and their assimilable nitrogen concentrations were 40, 120, 140 and $240 \mathrm{mg} / \mathrm{L}$.

\subsubsection{Tanks}

Fermentations were run at pilot scale in stainless steel tanks. The tanks contained $90 \mathrm{~L}$ of must and the headspace represented $30 \%$ of the total volume.

\subsubsection{Control of fermentation}

The $\mathrm{CO}_{2}$ released was automatically and continually measured with a gas mass flow meter and the rate of $\mathrm{CO}_{2}$ production $\left(\mathrm{dCO}_{2} / \mathrm{dt}\right)$ was calculated with a high level of precision. The fermentations were controlled in different ways:

(i) Constant rate fermentations (CRF): to control the stripping effect, constant rate fermentations were run at $20^{\circ} \mathrm{C}$. In these experiments, the rate of $\mathrm{CO}_{2}$ production was kept constant by a feedback control system involving the addition of ammoniacal nitrogen via a peristaltic pump (Ismatec Reglo) [15].

(ii) Isothermal fermentations (IF): the temperature was maintained at a constant value (20 and $30^{\circ} \mathrm{C}$ ), with a precision of $0.1^{\circ} \mathrm{C}$.

(iii) Anisothermal fermentations (AF): the temperature was regulated according to the $\mathrm{CO}_{2}$ production, which is proportional to the sugar degradation, with a slope of $0.2^{\circ} \mathrm{C} /(\mathrm{g} / \mathrm{L})$ of evolved $\mathrm{CO}_{2}$. This evolution of temperature simulated anisothermal conditions observed in

128 industrial-size tanks when the temperature rises freely until the final setpoint is reached [16]. Two anisothermal fermentations were run between 15 and $30^{\circ} \mathrm{C}$, thus covering the maximum range of temperatures used in winemaking. Another fermentation was conducted between 20 
and $30^{\circ} \mathrm{C}$, simulating a common temperature profile for red winemaking. All parameters and control conditions for the fermentation experiments in this study are summarized in Table $\mathbf{1 .}$

\subsection{Analysis of volatile compounds}

\subsubsection{Online measurements in the gas}

The gas was pumped at a flow rate of $14 \mathrm{~mL} / \mathrm{min}$ from the tank headspace through a heated transfer line and concentrated in a cold trap (Tenax TM) for 6 min (desorption at $160^{\circ} \mathrm{C}$ for $\left.1 \mathrm{~min}\right)$, and injected into a ZBWax $(60 \mathrm{~m} \times 0.32 \mathrm{~mm} \times 0.5 \mu \mathrm{m}$, Phenomenex Inc. $)$. The injector was kept at $200^{\circ} \mathrm{C}$. Helium was used as the carrier gas at a constant pressure of $120 \mathrm{kPa}$. The oven temperature program was $38^{\circ} \mathrm{C}$ for $3 \mathrm{~min}, 3^{\circ} \mathrm{C} / \mathrm{min}$ up to $65^{\circ} \mathrm{C}$, then $6^{\circ} \mathrm{C} / \mathrm{min}$ to $160^{\circ} \mathrm{C}$, held for $5 \mathrm{~min}$, then $8^{\circ} \mathrm{C} / \mathrm{min}$ up to $230^{\circ} \mathrm{C}$ and held for $5 \mathrm{~min}$. A flame ionisation detector (FID) was used at $260^{\circ} \mathrm{C}$.

The on-line GC system was calibrated by using a Sonimix 6000C1 (LNI Schmidlin SA). This equipment generates standard gases by dilution from standard gas bottles or permeation tubes. Standard gas bottles (Air Product) containing 4004, 85.1 and 100 mmol/Kmol of ethyl acetate (CAS number 141-78-6), isoamyl acetate (CAS number 12392-2) and isobutanol (CAS number 78-83-1), respectively, were used. A permeation tube with a permeation rate of $4831 \mathrm{ng} / \mathrm{min}$ at $45^{\circ} \mathrm{C}$ (LNI Schmidlin SA) was used to calibrate ethyl hexanoate (CAS number 123-66-0) concentration. The permeation tube was placed in an oven at $45^{\circ} \mathrm{C}$, and diluted with air at $51 \mathrm{~mL} / \mathrm{min}$.

\subsubsection{Measurements in the liquid}

$\mathrm{NaCl}(1 \mathrm{~g})$ was added to $3 \mathrm{~mL}$ of the fermentation sample in a $20 \mathrm{~mL}$ vial. To standardise the equilibrium conditions between the liquid and the headspace, the ethanol concentration in 
the vial was adjusted to $11 \%$ by adding $2 \mathrm{~mL}$ of a mixture of $12 \mathrm{~g} / \mathrm{L}$ tartaric acid solution diluted either in water or a ethanol/ water mix $(30 \% \mathrm{v} / \mathrm{v})$. Fifty $\mu \mathrm{L}$ of 4-Methylpentan-2-ol at a concentration $3 \mathrm{~g} / \mathrm{L}$ was added to the vial as an internal standard. The sample vial was heated and agitated for $5 \mathrm{~min}$ at $50^{\circ} \mathrm{C}$ in a headspace autosampler HT200 equipped with a gastight syringe, preheated to $60^{\circ} \mathrm{C}$. One $\mathrm{mL}$ of headspace gas was analysed by using a HP6890 GC coupled with a FID detector. The injector temperature was $240^{\circ} \mathrm{C}$. The GC oven was equipped with a BP20 column $\left(30 \mathrm{~m} \times 0.53 \mathrm{~mm} \times 1.0 \mu \mathrm{m}\right.$, SGE). $\mathrm{H}_{2}$ was used as the carrier gas at a constant flow rate of $4.8 \mathrm{~mL} / \mathrm{min}$. The oven temperature programme was $40^{\circ} \mathrm{C}$ for $3 \mathrm{~min}, 3^{\circ} \mathrm{C} / \mathrm{min}$ to $80^{\circ} \mathrm{C}, 15^{\circ} \mathrm{C} / \mathrm{min}$ to $160^{\circ} \mathrm{C}$ held for $1 \mathrm{~min}$, then $30^{\circ} \mathrm{C} / \mathrm{min}$ to $220^{\circ} \mathrm{C}$ and then held at $220^{\circ} \mathrm{C}$ for $2 \mathrm{~min}$. The detector was set at $250^{\circ} \mathrm{C}$. Peak areas were acquired with Agilent Chemstation software.

\subsection{Determinations of gas-liquid partition coefficients $\left(\mathrm{k}_{\mathrm{i}}\right)$}

The gas-liquid partition coefficients $\left(\mathrm{k}_{\mathrm{i}}\right)$ during fermentation were followed by dividing the volatile concentrations in the tank headspace by the concentrations in the liquid at various times. Several $\mathrm{k}_{\mathrm{i}}$ were also determined in samples taken at different stages of fermentation by using the Phase Ratio Variation (PRV) method in static conditions as previously described $[12,17]$

\subsection{Modelling}

The equations of the mathematical model (listed in the section Results) were implemented in a program written under Matlab 7 (The Matworks Inc., Natick, MA). The parameters were identified by nonlinear regression under Matlab, using the Statistic Toolbox. 


\section{Results and discussion}

\subsection{Model development}

\subsubsection{Effects of $\mathrm{CO}_{2}$ stripping and of must composition}

Morakul et al. [12] used synthetic solutions with increasing ethanol concentrations and decreasing sugar concentrations to simulate the evolution of the composition of must during fermentation. They showed that the gas-liquid partition coefficients $\left(\mathrm{k}_{\mathrm{i}}\right)$ of higher alcohols and esters continuously decreased as the composition of a model wine fermentation medium changed because the sugar induces 'salting out' of volatile compounds (at the beginning of a fermentation) whereas the ethanol increases their solubility, and thereby decreases their volatility. The authors also observed a decrease of the relative gas-liquid ratio of these molecules during fermentation. However, the ratios were expressed in arbitrary units and could not be directly compared to the values of $k_{i}$ obtained in synthetic solutions, without any release of $\mathrm{CO}_{2}$.

To complete this previous preliminary study, the first aim of the present work was to clarify the effect of stripping on gas-liquid partitioning of aroma compounds. The stripping effect is complex because, in usual fermentations, both the rate of $\mathrm{CO}_{2}$ production and other factors vary throughout the fermentation process. The problems associated with this complexity were overcome by controlling the rate of $\mathrm{CO}_{2}$ release. The effect of stripping was indeed isolated by running defined fermentations, in which the rate of $\mathrm{CO}_{2}$ production was kept constant by perfusion of ammoniacal nitrogen controlled. By modifying the amount of 
(CRF-0.3 and CRF-0.6) in which the rates of $\mathrm{CO}_{2}$ production were kept constant at $0.3 \mathrm{~g} / \mathrm{L} . \mathrm{h}$ and $0.6 \mathrm{~g} / \mathrm{L} . \mathrm{h}$ respectively. The rate of $\mathrm{CO}_{2}$ production was regulated between 10 and $85 \%$ of the fermentation progress. Fig. 1 compares the evolution of the $\mathrm{CO}_{2}$ production rate (i) in these two fermentations and in (ii) an isothermal fermentation at $20^{\circ} \mathrm{C}$, without any control of the $\mathrm{CO}_{2}$ production rate (IF-20-B).

Changes in gas-liquid concentration ratios of ethyl acetate, isoamyl acetate, ethyl hexanoate and isobutanol were compared in these three different fermentation conditions. They were also compared to the values of $\mathrm{k}_{\mathrm{i}}$ calculated by the static headspace PRV method in samples taken during fermentation. In these samples, $\mathrm{k}_{\mathrm{i}}$ was measured at equilibrium, in the absence of $\mathrm{CO}_{2}$ release. Fig. 2 shows the results obtained for isobutanol and isoamyl acetate,

216 the following observations being also valid for the other volatile molecules (data not shown).

217 A very remarkable result was that (i) almost identical decreases in $k_{i}$ with increasing ethanol concentration were observed whatever the $\mathrm{CO}_{2}$ production rate and (ii) values of the partition coefficients were close to those obtained at equilibrium without any $\mathrm{CO}_{2}$ release. It can therefore be concluded that stripping did not significantly change the gas-liquid partitioning of aroma compounds during fermentation and that the two phases always remained at equilibrium throughout the process in spite of the $\mathrm{CO}_{2}$ flux.

Therefore, at constant temperature, the values of $\mathrm{k}_{\mathrm{i}}$ which reflect changes in the gas-liquid partitioning of aroma compounds in fermenting musts only result from changes in the composition of the liquid phase, that is the decreasing sugar concentration and increasing ethanol concentration.

Consequently, at constant temperature, the evolution of $\mathrm{k}_{\mathrm{i}}$ can be written as follows:

$$
k_{i}=A \times E+B
$$

where $\mathrm{A}$ and $\mathrm{B}$ are constants depending on the considered compound $\mathrm{i}$, and $\mathrm{E}$ is the ethanol concentration $(\mathrm{g} / \mathrm{L})$ in the liquid phase, which is proportional to the sugar consumption and 
$\mathrm{CO}_{2}$ production. $\mathrm{E}$ is therefore representative of the whole matrix effect corresponding to the

232 modification of the ethanol and sugar concentrations.

\subsubsection{Effect of temperature}

Gas-liquid partitioning not only depends on the composition of the liquid phase; it is also strongly affected by the temperature. For a constant medium composition, the ClausiusClapeyron law is usually applied to the changes in partition coefficient $\left(\mathrm{k}_{\mathrm{i}}\right)$ with temperature [19]:

$$
-\frac{d\left(\ln k_{i}\right)}{d(1 / T)}=\frac{\Delta \mathrm{H}_{v a p}}{R} \quad \text { or } \ln k_{i}=C-\frac{\Delta \mathrm{H}_{v a p}}{R \times T}
$$

Where $\Delta \mathrm{H}_{\text {vap }}$ is the phase change enthalpy of the volatile compound expressed in $\mathrm{J} / \mathrm{mol}$, $\mathrm{T}$ is the absolute temperature $(\mathrm{K}), \mathrm{R}$ is the perfect gas constant $(8.413 \mathrm{~J} / \mathrm{mol} . \mathrm{K})$ and $\mathrm{C}$ is a constant.

Nevertheless, Morakul et al. [12] showed that, in synthetic media, the value of the parameter $\Delta \mathrm{H}_{\text {vap }}$ is not constant. For example, the $\Delta \mathrm{H}_{\text {vap }}$ of isobutanol was $71.4 \mathrm{~kJ} / \mathrm{mol}$ in a synthetic medium simulating a grape juice and $37.8 \mathrm{~kJ} / \mathrm{mol}$ in a synthetic medium simulating a wine. As a consequence, the effect of the temperature on the gas-liquid partitioning not only depends on the temperature but is also a function of the composition of the liquid phase. So, the classical Clausius-Clapeyron expression was modified to introduce the dependence of the values $\mathrm{C}$ and $\Delta \mathrm{H}_{\text {vap }}$ on the medium composition:

$$
\ln k_{i}=D 1+D 2 \times E-\frac{D 3+D 4 \times E}{R \times T}
$$

Where $\mathrm{T}$ is the absolute temperature and D1, D2, D3 and D4 are constants. To give a clearer physical meaning to the parameters of the model, we modified the previous equation by including a reference temperature $\left(\mathrm{T}_{\text {ref }}\right)$, so the model expression became: 


$$
\ln k_{i}=F 1+F 2 \times E-\frac{F 3+F 4 \times E}{R}\left(\frac{1000}{T}-\frac{1000}{T_{r e f}}\right)
$$

Where $\mathrm{T}$ is the current absolute temperature, $\mathrm{T}_{\text {ref }}$ corresponds to the absolute reference temperature, i.e $293 \mathrm{~K}\left(20^{\circ} \mathrm{C}\right)$ in this study and F1, F2, F3 and F4 are constants. F1 is the logarithm of the partition coefficient $\left(\operatorname{lnk}_{\mathrm{i}}\right)$ at the reference temperature in the initial must $(\mathrm{E}=$ 0). F2 represents the sensitivity of the partition coefficient to medium composition at the reference temperature. $\mathrm{F} 3$ corresponds to the value of $\Delta \mathrm{H}_{\mathrm{vap}}$ in the initial must $(\mathrm{E}=0), \Delta \mathrm{H}_{\mathrm{vap}}$ giving the sensitivity of $\mathrm{k}_{\mathrm{i}}$ to changes in temperature. $\mathrm{F} 4$ represents the sensitivity of $\Delta \mathrm{H}_{\mathrm{vap}}$ to changes in medium composition, described here as the ethanol concentration. The arbitrary factor 1000 was introduced for numerical convenience, to have numeric parameter values (F1-F4) of order of one. This generally favours reliable identification with nonlinear regression software. This factor can be of course absorbed into the values of F3 and F4.

The mathematical expression detailed in Equation 4 was then used in the subsequent steps to model the evolution of the $\mathrm{k}_{\mathrm{i}}$ values for ethyl acetate, isoamyl acetate, ethyl hexanoate and isobutanol throughout the wine fermentation as a function both of the ethanol production and of the temperature.

\subsection{Model identification}

Model parameters in Equation 4 were determined simultaneously by nonlinear regression based on the values of the $\mathrm{k}_{\mathrm{i}}$ (in concentration ratio) obtained from three experiments (i) isothermal fermentation at $20^{\circ} \mathrm{C}$ (IF-20-A) (ii) isothermal fermentation at $30^{\circ} \mathrm{C}$ (IF-30) and (iii) anisothermal fermentations between 15 and $30^{\circ} \mathrm{C}$ (AF-15-30). All $\mathrm{k}_{\mathrm{i}}$ measurements (41 values, including 14 from IF-20-A, 11 from IF-30 and 16 from AF-15-30) were used to determine the parameters F1-F4 together with their standard errors (Table 2). 
The estimated values of F1 were consistent with the values of $1 n k_{i}$ measured by the PRV method [12] in static conditions in the must at the beginning of fermentation $(-5.11,-3.94$, 3.68 and -7.72 for ethyl acetate, isoamyl acetate, ethyl hexanoate and isobutanol,

282

respectively). Among the volatile compounds studied, ethyl hexanoate had the highest $\ln \mathrm{k}_{\mathrm{i}}$ consistent with the higher volatility of this compound whereas isobutanol, which had a lower value of $\ln k_{i}$, is always less volatile than esters.

F2 values were negative, indicating that $\mathrm{k}_{\mathrm{i}}$ decreased as the ethanol concentration increased. The most negative value indicates the greatest sensitivity of $\mathrm{k}_{\mathrm{i}}$ to the changes in liquid composition. Ethyl hexanoate was the molecule most affected by the liquid composition $\left(\mathrm{F} 2=-1.39 \times 10^{-2}\right)$ and ethyl acetate and isobutanol were less sensitive with $\mathrm{F} 2$ values of $-2.90 \times 10^{-3}$ and $-4.10 \times 10^{-3}$, respectively. This sensitivity is seemingly related to the hydrophobicity of the molecule. Indeed, the hydrophobicity constant values $\left(\operatorname{LogK}_{\mathrm{ow}}\right.$ at $25^{\circ} \mathrm{C}$ ), i.e. $0.76,0.73,2.25$ and 2.83 , for isobutanol, ethyl acetate, isoamyl acetate and ethyl hexanoate, respectively (SRC Interactive PhysProp database, Syracuse), are in the same order as F2.

The values of $\mathrm{F} 3$ representing the sensitivity of $\mathrm{k}_{\mathrm{i}}$ to the temperature, were compared to previously reported $\Delta \mathrm{H}_{\text {vap }}$ values [12]. The $\Delta \mathrm{H}_{\text {vap }}$ was $39,39.4,67.5$ and $71.4 \mathrm{~kJ} / \mathrm{mol}$ for ethyl acetate, isoamyl acetate, ethyl hexanoate and isobutanol, respectively. Although the values are in the same order of magnitude as our F3 values, there are differences of about $20 \%$ for isoamyl acetate, ethyl hexanoate and isobutanol. These differences between $\mathrm{F} 3$ and $\Delta \mathrm{H}_{\mathrm{vap}}$ may be a consequence of the differences in the matrix used, as the F3 values were identified using the natural must whereas $\Delta \mathrm{H}_{\text {vap }}$ were calculated using a synthetic medium which contained only sugar and weak acids to simulate the must at the start of the fermentation. The difference between $\mathrm{F} 3$ and $\Delta \mathrm{H}_{\text {vap }}$ for ethyl acetate is higher than $40 \%$, and this might be due to an atypical behaviour of this compound. Indeed, temperature had little influence on the 
value of $k_{i}$ of ethyl acetate and therefore, it is difficult to determine precisely the values of F3 and F4.

A sensitivity analysis of the model was conducted to assess the effect and the relative importance of the model parameters. Average conditions $\left(\mathrm{T}=25^{\circ} \mathrm{C}\right.$ and ethanol concentration $\mathrm{E}=45 \mathrm{~g} / \mathrm{L})$ were selected and each parameter (F1-F4) was arbitrarily increased by $30 \%$. As expected, parameter F1 (directly related to the partition value) had the higher sensitivity, comprised between $64 \%$ for ethyl hexanoate and $92 \%$ for isobutanol. Its knowledge is thus the most important for accurately predicting $\mathrm{k}_{\mathrm{i}}$. The second most important parameter (between 10 and 16\% sensitivity) was F3, confirming the usually reported fact that temperature has a significant effect on volatility. The effect of the medium composition expressed via F2 was similar (between 4\% for ethyl acetate and 17\% for ethyl hexanoate). Finally, parameter F4 was found to have some effect only for ethyl acetate (4\%), and less than $1 \%$ for the other compounds studied; this is consistent with the model identification results indicating that a significantly different from zero value of F4 could only be determined for ethyl acetate.

\subsection{Model validation}

After parameter identification, the variation of $\mathrm{k}_{\mathrm{i}}$ as a function of ethanol concentration and temperature, according to equation 4, was plotted. Fig. 3 shows the plot for fermentations used for parameter identification and Fig. 4 that for independent fermentations: (i) isothermal fermentation at $20^{\circ} \mathrm{C}$ (IF-20-B) and (ii) anisothermal fermentation between 20 and $30^{\circ} \mathrm{C}$ (AF20-30).

The mean relative error between model prediction values and the measured values was calculated as follows: 
Where $\mathrm{n}$ is the number of $\mathrm{k}_{\mathrm{i}}$ measurements used for model validation. Table 3 indicates that (i) the average differences between the experimental and the calculated values were less than $10 \%$ for isoamyl acetate, ethyl hexanoate and isobutanol and (ii) the precision of the $\mathrm{k}_{\mathrm{i}}$ estimations was comparable for data from experiments not used for parameter identification. These results demonstrate the value of the model to predict $\mathrm{k}_{\mathrm{i}}$ with a good accuracy for these 3 compounds. The prediction was much less satisfactory for ethyl acetate with differences up to $33 \%$, due to an atypical behaviour of this compound.

One of the main reasons why predicting $\mathrm{k}_{\mathrm{i}}$ is valuable is that it allows calculation of the concentrations of volatiles in the gas phase from measurements in the liquid, and the reverse. It is therefore possible to calculate the global production by adding the volatile concentration in the liquid to the amount lost in the gas phase (Equation 6):

$$
\text { Losses }=\frac{\int_{0}^{t_{\text {eal }}} C^{\text {gas }}(t) \times Q(t) \times d t}{C^{\text {liq }}\left(t_{\text {end }}\right)+\int_{0}^{t_{\text {epd }}} C^{\text {gas }}(t) \times Q(t) \times d t} \times 100 \%
$$

Where $\mathrm{t}$ is the current time $(\mathrm{h}), \mathrm{t}_{\text {end }}$ is the final time $(\mathrm{h}), C^{\text {gas }}(t)$ is the concentration of volatile compound in the gas phase at time $t$ expressed in $\mathrm{mg} / \mathrm{L}$ of $\mathrm{CO}_{2}, Q(t)$ is the $\mathrm{CO}_{2}$ specific flow rate at time $\mathrm{t}$ expressed in $\left(\mathrm{L}\right.$ of $\mathrm{CO}_{2} / \mathrm{L}$ of must $) / \mathrm{h}$ and $C^{\text {liq }}$ is the total concentration of the volatile compound in the must at the end of the fermentation $(\mathrm{mg} / \mathrm{L}$ of must).

347 The relative amount of volatiles lost, i.e the ratio of losses to total production, is of particular technological interest. Table 4 compares measured (using concentrations in the gas) and predicted (using $\mathrm{k}_{\mathrm{i}}$ values and concentrations in the liquid) loss values. The predicted losses were very close to the values measured, illustrating the accuracy of the model. The 
amounts of lost volatile in the gas phase varied with the volatility of the compounds: it was negligible in the case of isobutanol but was $70 \%$ for ethyl hexanoate at $30^{\circ} \mathrm{C}$.

\section{Conclusion}

The gas-liquid partitioning of the main aroma compounds produced during winemaking fermentations, namely isobutanol, isoamyl acetate, ethyl hexanoate and to a lesser extent ethyl acetate, was accurately predicted by the model. The model, based on the effects of changes to the matrix and temperature during fermentation, allowed estimation of the partition coefficient $\left(\mathrm{k}_{\mathrm{i}}\right)$ with less than $10 \%$ error, except for ethyl acetate. The benefits of predicting $\mathrm{k}_{\mathrm{i}}$ include allowing the calculation of the total production of the volatile compounds from a single measure (concentration in the gas or in the liquid phase). This is particularly advantageous in the case of on-line monitoring of the main aroma compounds in the gas, as described by Mouret et al. [2]. The ability to calculate the total production and to differentiate between the amounts remaining in the liquid and those lost in the $\mathrm{CO}_{2}$ are major issues for improving our understanding of yeast metabolism and optimising fermentation control. From a microbiological point of view, the total amount produced needs to be considered whereas, from a technological point of view, the concentration remaining in the wine is more important. For some molecules, such as isobutanol, the losses in the gas are negligible but for more volatile compounds, in particular esters, such losses can represent a very significant proportion of the total production. Minimising these losses, by optimizing the fermentation control, particularly the temperature profile, is a significant challenge. The objective is to find the best compromise between fermentation kinetics and aroma production. The development of metabolic models predicting the synthesis of aroma compounds [20], in combination with 
375 the model of gas-liquid partitioning and with a kinetic model [21] represents a complex but

376 very promising prospect.

377

\section{Acknowledgements}

379

This research was funded by the European Union Seventh Framework Programme (FP7/2007-2013), under grant no. KBBE-212754.

\section{References}

[1] Swiegers JH, Bartowsky EJ, Henschke PA, Pretorius IS. Yeast and bacterial modulation of wine aroma and flavour. Aust J Grape Wine Res 2005; 11: 139-173.

[2] Mouret J-R, Nicolle P, Angenieux M, Aguera E, Perez M, Sablayrolles J-M. On-line measurement of 'quality markers' during winemaking fermentations. International Intervitis Interfructa Congress, March 24-26, 2010, Stuttgart, Germany.

[3] Gee DA, Ramirez WF. A flavour model for beer fermentation. J Inst Brew 1994; 100: 321-329.

[4] Trelea IC, Latrille E, Landaud S, Corrieu G. Reliable estimation of the key variables and of their rates of change in alcoholic fermentation. Bioprocess Biosyst Eng 2001; 24: 227-237.

394 fermentation. J Process Control 2004; 14: 1-16.

395 [6] Banavara DS, Rabe S, Krings U, Berger RG. Modeling dynamic flavor release from 396 water. J Agric Food Chem 2002; 50: 6448-6452.

[7] Marin M, Baek I, Taylor AJ. Volatile release from aqueous solutions under dynamic headspace dilution conditions. J Agric Food Chem 1999; 47: 4750-4755. 
[8] Nahon DF, Harrison M, Roozen JP. Modeling flavor release from aqueous sucrose

400 solutions, using mass transfer and partition coefficients. J Agric Food Chem 2000; 48: 12784011284.

402

403

404

405

406

407

408

409

410

411

412

413

414

415

416

417

418

[9] Robinson AL, Ebeler SE, Heymann H, Boss PK, Solomon PS, Trengove RD. Interactions between wine volatile compounds and grape and wine matrix components influence aroma compound headspace partitioning. J Agric Food Chem 2009; 57: 10313-10322.

[10] Tsachaki M, Gady A-L, Kalopesas M, Linforth RST, Athes V, Marin M, Taylor AJ. Effect of ethanol, temperature, and gas flow rate on volatile release from aqueous solutions under dynamic headspace dilution conditions. J Agric Food Chem 2008; 56: 5308-5315. [11] Tsachaki M, Linforth RST, Taylor AJ. Aroma release from wines under dynamic conditions. J Agric Food Chem 2009; 57: 6976-6981.

[12] Morakul S, Athes V, Mouret J-R, Sablayrolles J-M. Comprehensive study of the evolution of gas-liquid partitioning of aroma compounds during wine alcoholic fermentation. J Agric Food Chem 2010; 58: 10219-10225.

[13] Ferreira V, Pena C, Escudero A, Cacho J. Losses of volatile compounds during fermentation. Z Lebensm-Unters Forsch 1996; 202: 318-323.

[14] Francis IL, Newton JL. Determining wine aroma from compositional data. Aust J Grape Wine Res 2005; 11: 114-126.

[15] Manginot C, Sablayrolles JM, Roustan JL, Barre P. Use of constant rate alcoholic fermentations to compare the effectiveness of different nitrogen sources added during the stationary phase. Enzyme Microb Technol 1997; 20: 373-380.

[16] Sablayrolles JM, Barre P. Kinetics of alcoholic fermentation under anisothermal conditions.2. Prediction from the kinetics under isothermal conditions. Am J Enol Vitic 1993; 44: 134-138. 

experimental methods for measuring infinite dilution volatilities of aroma compounds in water/ethanol mixtures. J Agric Food Chem 2004; 52: 2021-2027. [18] El Haloui N, Picque D, Corrieu G. Alcoholic fermentation in winemaking: On-line

427 measurement of density and carbon dioxide evolution. J Food Eng 1988; 8: 17-30. [19] Meynier A, Garillon A, Lethuaut L, Genot C. Partition of five aroma compounds

429 between air and skim milk, anhydrous milk fat or full-fat cream. Lait 2003; 83: 223-235.

430 [20] Charnomordic B, David R, Dochain D, Hilgert N, Mouret J-R, Sablayrolles J-M, Vande

431 Wouwer A. Two modelling approaches of winemaking: first principle and metabolic

432 engineering. Math Comp Model Dyn 2010; 16: 535 - 553.

433 [21] Malherbe S, Fromion V, Hilgert N, Sablayrolles, J-M. Modeling the effects of 434 assimilable nitrogen and temperature on fermentation kinetics in enological conditions.

435 Biotechnol and Bioeng 2004; 86: 261-272.

436 


\section{Figure captions}

Fig 1-1. Evolution of the $\mathrm{CO}_{2}$ production rate as a function of ethanol concentration, for a standard fermentation IF-20-B (...), and for constant rate fermentations at $\mathrm{CO}_{2}$ production rates of $0.3 \mathrm{~g} / \mathrm{L} . \mathrm{h} \mathrm{CRF-0.3}(+)$ and $0.6 \mathrm{~g} / \mathrm{L} . \mathrm{h} \mathrm{CRF}-0.6(--)$ and assimilable nitrogen concentration added to control the $\mathrm{CO}_{2}$ production rate (-). Initial assimilable nitrogen concentrations in the musts: 240,40 and $120 \mathrm{mg} / \mathrm{L}$. Temperature: $20^{\circ} \mathrm{C}$.

Fig 2. Changes in gas-liquid ratio $\left(\mathrm{k}_{\mathrm{i}}\right)$ as a function of ethanol concentration for isoamyl acetate (A) and isobutanol (B); standard fermentation IF-20-A ( $\times$ ), constant rate fermentation $20^{\circ} \mathrm{C}$.

Fig 3. Comparison of predicted and measured $\mathrm{k}_{\mathrm{i}}$ for isoamyl acetate $(\mathrm{B})$

(B) and isobutanol (C) in fermentations run at different fermentation temperatures (A) for model identification. (B) and (C) show predicted (...) and measured ( $\square$ ) $\mathrm{k}_{\mathrm{i}}$ during an isothermal fermentation at $20^{\circ} \mathrm{C}$ (IF20-A); predicted (---), measured $(\bullet) \mathrm{k}_{\mathrm{i}}$ during an anisothermal fermentation run between $15-$ $30^{\circ} \mathrm{C}$ (AF-15-30); predicted ( $(-)$, measured $(\times) \mathrm{k}_{\mathrm{i}}$ during an isothermal fermentation at $30^{\circ} \mathrm{C}(\mathrm{IF}-30)$.

Fig 4. Comparison of predicted and measured values for $\mathrm{k}_{\mathrm{i}}$ for isoamyl acetate (B) and isobutanol (C) in fermentations run at different fermentation temperatures (A) for model validation. (B) and (C) show predicted (...) and measured ( $\square$ ) $\mathrm{k}_{\mathrm{i}}$ during an isothermal 458 fermentation at $20^{\circ} \mathrm{C}(\mathrm{IF}-20-\mathrm{B})$; predicted (-- ), measured $(\bullet) \mathrm{k}_{\mathrm{i}}$ during an anisothermal fermentation run between $20-30^{\circ} \mathrm{C}$ (AF-20-30). The (A) graph shows temperature profiles for the two fermentation runs IF-20-B and AF-20-30. 
1 Table 1. Experimental conditions of the fermentation trials, used for model identification and

2 for model validation.

\begin{tabular}{|c|c|c|c|}
\hline Fermentations & $\begin{array}{l}\text { Initial assimilable } \\
\text { nitrogen }(\mathrm{mg} / \mathrm{L})\end{array}$ & $\begin{array}{c}\text { Regulated } \\
\text { temperature }\left({ }^{\circ} \mathrm{C}\right)\end{array}$ & Identification / validation \\
\hline
\end{tabular}

Constant rate fermentations $(\mathrm{CRF})^{\mathrm{a}}$
1) $\mathrm{CRF}-0.3$
40
20
2) CRF-0.6
120
20

Isothermal fermentations (IF) ${ }^{\mathrm{b}}$
3) IF-20-A
140
20
Model identification
4) IF-20-B
240
20
Model validation
5) IF-30
240
30
Model identification

Anisothermal fermentations $(\mathrm{AF})^{\mathrm{c}}$
6) $\mathrm{AF}-15-30$
140
15 to 30
Model identification
7) $\mathrm{AF}-20-30$
140
20 to 30
Model validation

$3{ }^{\mathrm{a}}$ The rate of $\mathrm{CO}_{2}$ production was kept constant at 0.3 and $0.6 \mathrm{~g} / \mathrm{L}$.h by addition of ammoniacal

4 nitrogen

$5 \quad{ }^{\mathrm{b}}$ The temperature during fermentation was regulated at the indicated constant values

$6{ }^{\mathrm{c}}$ The fermentation temperature was increased by $0.2^{\circ} \mathrm{C}$ per $\mathrm{g} / \mathrm{L}$ of $\mathrm{CO}_{2}$ produced 
1 Table 2. Numerical values for the model parameters identified from Equation 4 and given

2 with their standard error.

\begin{tabular}{lcccc}
\hline Parameter & Ethyl acetate & Isoamyl acetate & Ethyl hexanoate & Isobutanol \\
\hline F1 (-) & $-6.11 \pm 0.07$ & $-3.98 \pm 0.03$ & $-3.09 \pm 0.31$ & $-8.45 \pm 0.03$ \\
F2 (g/L) & $-2.9 \times 10^{-3} \pm 1.2 \times 10^{-3}$ & $-9.6 \times 10^{-3} \pm 0.5 \times 10^{-3}$ & $-1.39 \times 10^{-2} \pm 0.06 \times 10^{-2}$ & $-4.1 \times 10^{-3} \pm 0.5 \times 10^{-3}$ \\
F3 (kJ/mol & $71 \pm 9$ & $49 \pm 4$ & $55 \pm 4$ & $53 \pm 4$ \\
F4 (kJ mol/g.L) & $-4.4 \times 10^{-1} \pm 1.5 \times 10^{-1}$ & $-1.7 \times 10^{-3} \pm 59 \times 10^{-3 *}$ & $8.6 \times 10^{-2} \pm 6.1 \times 10^{-2 *}$ & $6.4 \times 10^{-3} \pm 60 \times 10^{-3 *}$
\end{tabular}

$3 *$ A standard error leading to the value zero being included in the $95 \%$ confidence interval

4 means that the parameter is not significantly different from zero.

5 
1 Table 3. Mean relative errors (\%) between predicted and measured $\mathrm{k}_{\mathrm{i}}$ calculated according to

2 equation 5 , with $\mathrm{n}$ : number of $\mathrm{k}_{\mathrm{i}}$ measurements per fermentation.

\begin{tabular}{|c|c|c|c|c|c|c|c|c|}
\hline \multirow[t]{2}{*}{ Fermentations } & \multicolumn{2}{|c|}{ Ethylacetate } & \multicolumn{2}{|c|}{ Isoamylacetate } & \multicolumn{2}{|c|}{ Ethyl hexanoate } & \multicolumn{2}{|c|}{ Isobutanol } \\
\hline & $\%$ & $\mathrm{n}$ & $\%$ & $\mathrm{n}$ & $\%$ & $\mathrm{n}$ & $\%$ & $\mathrm{n}$ \\
\hline \multicolumn{9}{|c|}{ Fermentations used for model identification } \\
\hline Anisothermal $15-30^{\circ} \mathrm{C}$ & 12.8 & 16 & 4.13 & 16 & 4.1 & 16 & 3.28 & 16 \\
\hline Isothermal at $20^{\circ} \mathrm{C}$ & 13.5 & 14 & 5.15 & 14 & 6.5 & 14 & 6.23 & 14 \\
\hline Isothermal at $30^{\circ} \mathrm{C}$ & 14.5 & 11 & 3.47 & 10 & 7.0 & 12 & 4.63 & 12 \\
\hline Mean & 13.5 & & 4.25 & & 5.7 & & 4.65 & \\
\hline \multicolumn{9}{|c|}{ Independent fermentations used for model validation only } \\
\hline Anisothermal $20-30^{\circ} \mathrm{C}$ & 17.2 & 11 & 9.07 & 11 & 6.6 & 11 & 7.94 & 11 \\
\hline Isothermal at $20^{\circ} \mathrm{C}$ & 32.8 & 10 & 5.77 & 10 & 4.2 & 10 & 4.92 & 10 \\
\hline Mean & 24.7 & & 7.42 & & 5.4 & & 6.50 & \\
\hline
\end{tabular}

3 
1 Table 4. Volatile compound losses (\%). Comparison of predicted* (pred.) and measured** 2 (meas.) values for losses, in \%.

\begin{tabular}{lcccccccc}
\hline Experiments & \multicolumn{2}{c}{ Ethyl acetate } & \multicolumn{2}{l}{ Isoamyl acetate } & \multicolumn{2}{l}{ Ethyl hexanoate } & \multicolumn{2}{c}{ Isobutanol } \\
\cline { 2 - 8 } & pred. & meas. & pred. & meas. & pred. & meas. & pred. & meas. \\
\hline Anisothermal $15-30^{\circ} \mathrm{C}$ & 7.48 & 6.87 & 33.3 & 33.7 & 54.2 & 54.3 & 0.66 & 0.65 \\
Isothermal at $20^{\circ} \mathrm{C}$ & 5.86 & 6.02 & 25.2 & 25.6 & 44.6 & 44.4 & 0.55 & 0.54 \\
Isothermal at $30^{\circ} \mathrm{C}$ & 13.6 & 13.0 & 44.1 & 42.2 & 70.9 & 71.0 & 1.33 & 1.33 \\
\hline Anisothermal $20-30^{\circ} \mathrm{C}$ & 10.5 & 12.5 & 45.0 & 46.7 & 66.3 & 64.7 & 0.93 & 1.01 \\
Isothermal at $20^{\circ} \mathrm{C}$ & 5.59 & 8.73 & 27.1 & 26.2 & 46.2 & 45.3 & 0.63 & 0.63
\end{tabular}

3 *Predicted losses were calculated from $\mathrm{k}_{\mathrm{i}}$ values and concentrations of the volatiles in the 4 liquid.

$5 * *$ Measured losses were calculated from concentrations of the volatiles in the gas. 
Fig 1

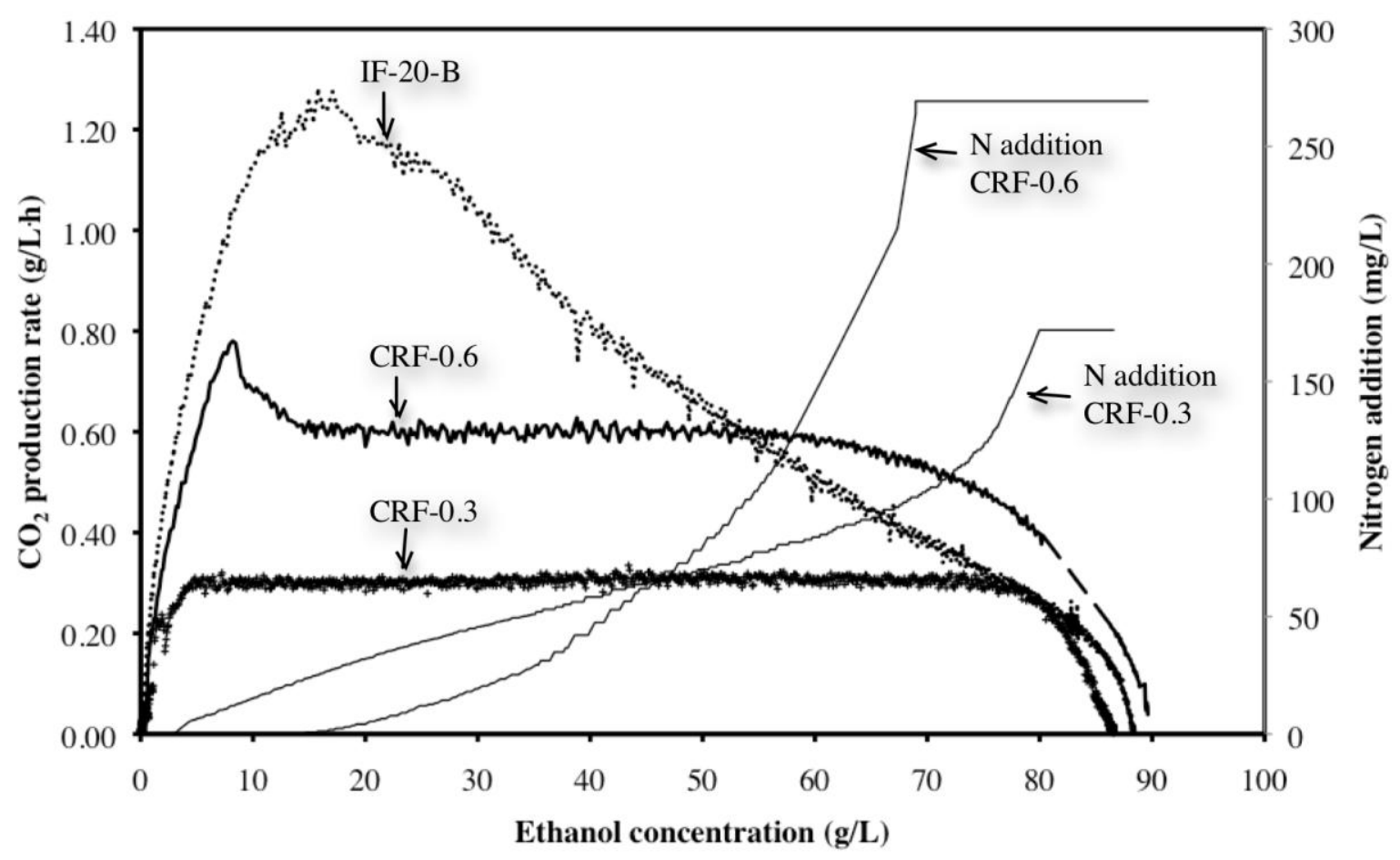


Fig 2.

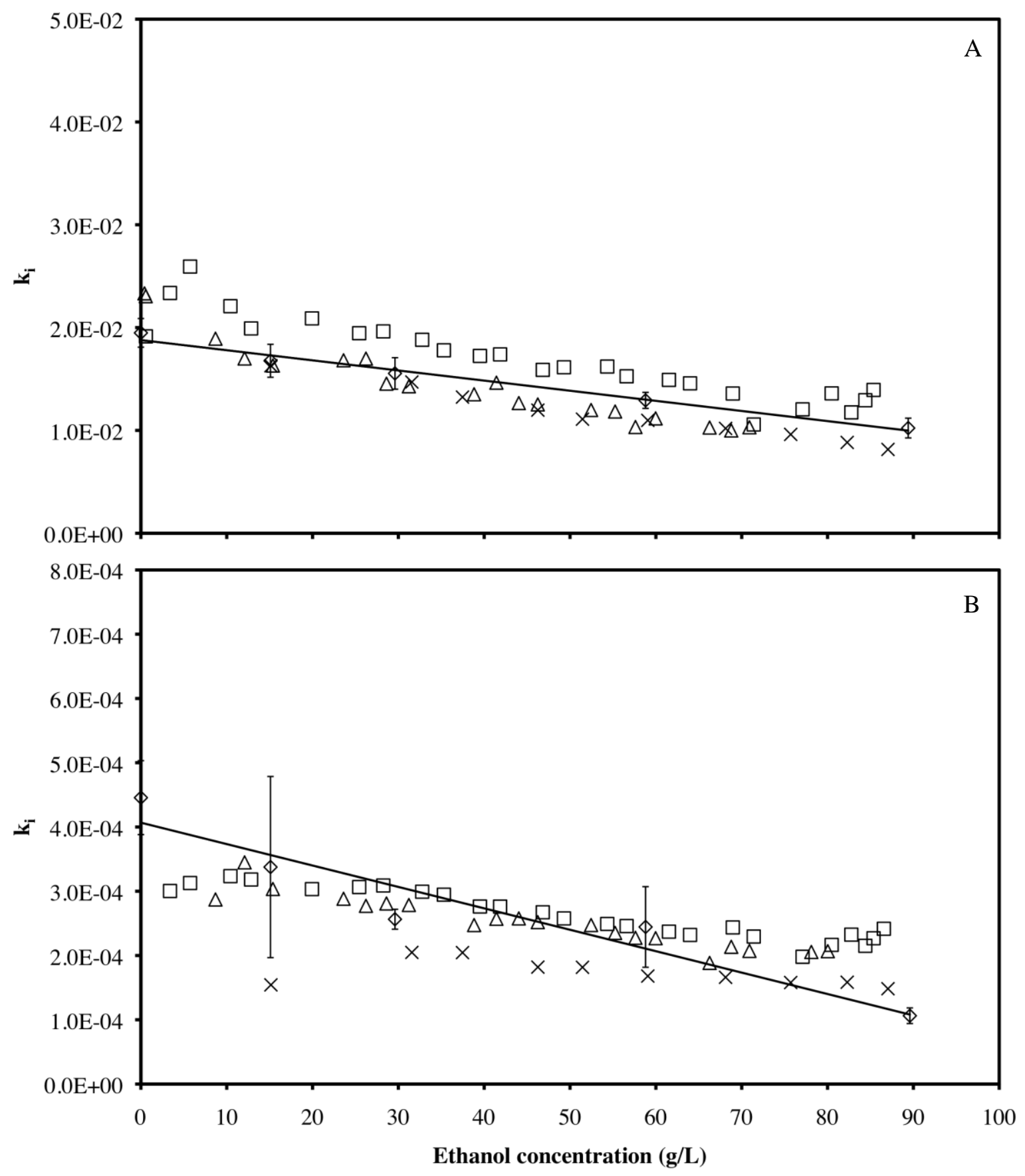


Fig 3
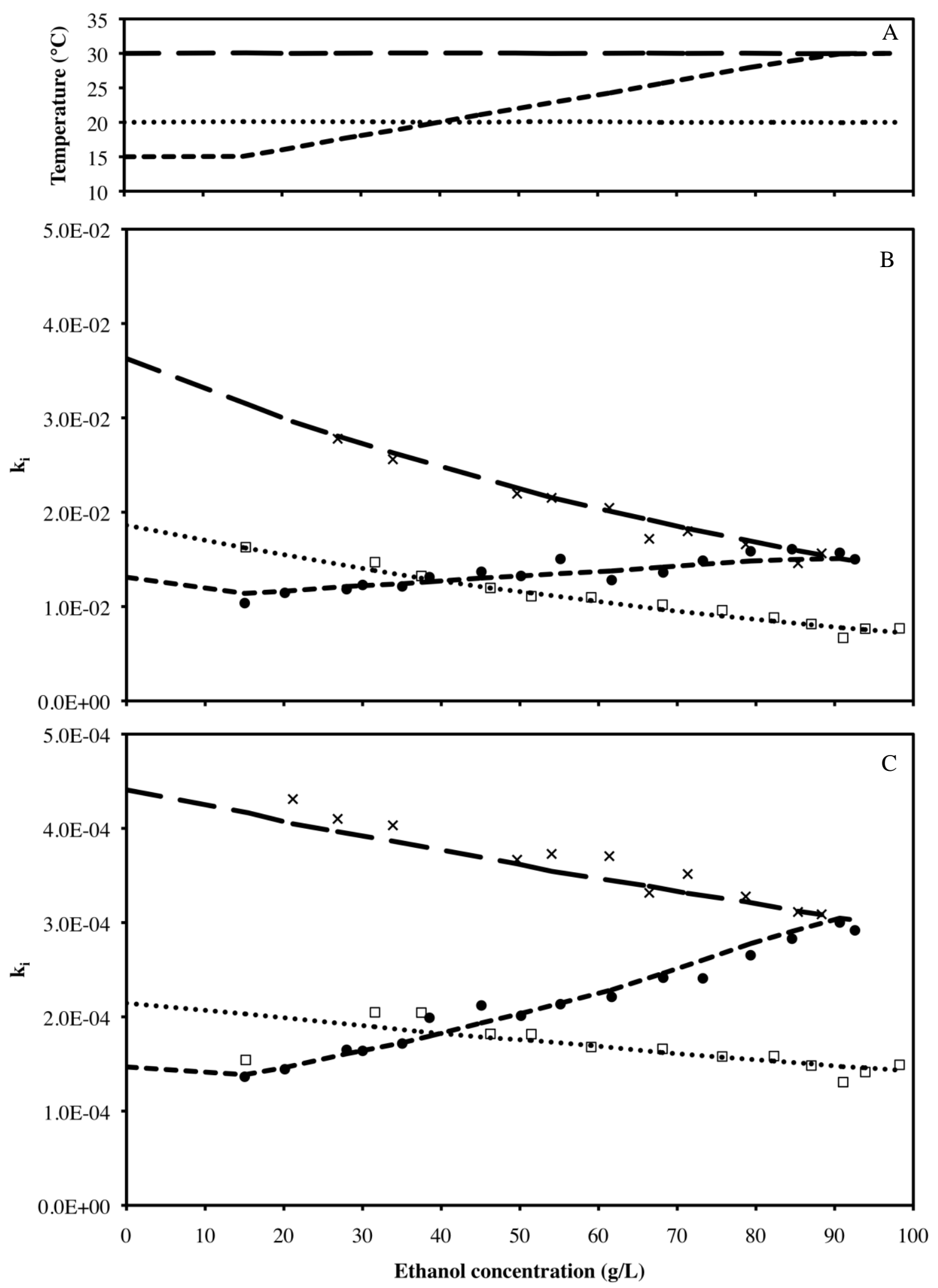
Fig 4.
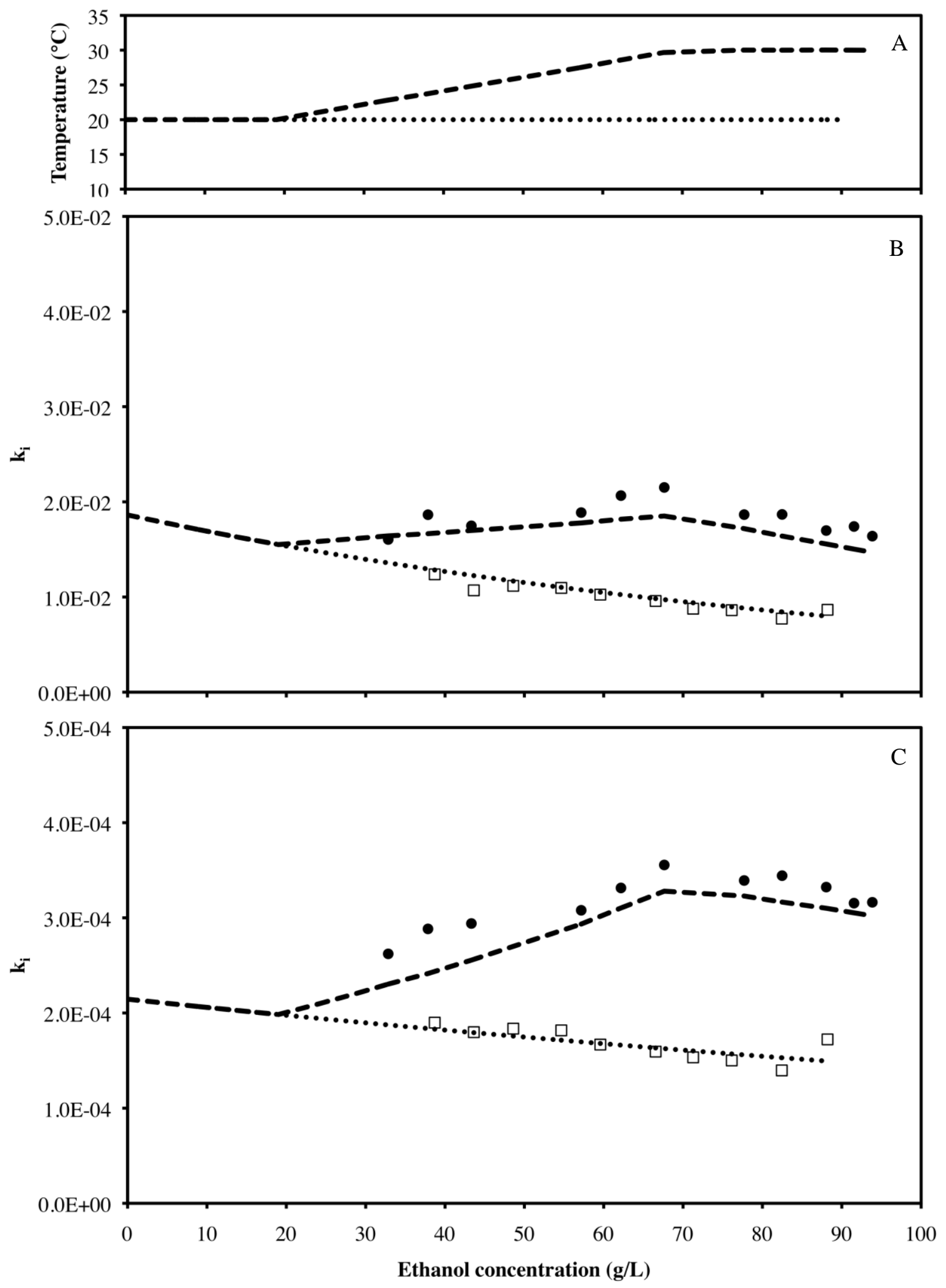